\title{
Reconstrução total de lábio superior e columela com retal ho muscul ocutâneo em ilha do depressor do ângulo da boca
}

\author{
M. Sabino Neto, H.T. de Castilho, E.B. Garcia, L.M. Ferreira \\ Disciplina de Cirurgia Plástica da Universidade F ederal de São Paulo - Escola Paulista de Medicina, São Paulo, SP.
}

\begin{abstract}
RESUMO - Os autores relatam caso de paciente que, após várias ressecções prévias de carcinomas de face, evolui u com deformidade do lábio superior, com comprometimento estéti co e funcional. Associadamente, apresentava perda total da columela.
\end{abstract}

\section{INTRODUÇÃO}

A reconstrução labial é procedimento freqüente e sua dificuldade está relacionada ao tamanho e localização da perda de substância.

A reparação da perda total de lábio envolve procedimentos mais complexos, que podem gerar deformidades em outras regiões da face ou mesmo a distância.

Poucas são as opções técnicas para a reconstrução total do lábio superior e que transfiram tecido suficiente e com características semel hantes, como a presença de pêlos.

Apresenta-se, aqui, caso de um paciente que, após várias ressecções prévias de tumores de face, apresentava deformidade do lábio superior, caracterizada por deficiência tecidual na regiãolabial, e com déficit funcional e estético, associado a perda total da columela.

Tal deformidade foi reparada por um novo retalho, baseado no músculo depressor do ângulo da boca.

\section{APRESE NTAÇÃO DO CASO}

S.O., 64 anos, masculino, branco, natural e procedente de São Paulo, já havia sido submetido previamente a um total de 14 procedimentos anteriores para a ressecção e reparação de carcinomas de pele na face. Estes levaram a deformidades, principalmente em lábio superior, e perda da columela.

O paciente procurou nosso serviço, queixando-se da dificuldade para abrir a boca, ausência de pilificação e alteração do vermelhão do lábio. Referia, também, interesse de reconstrução da columela.

Por apresentar várias outras cirurgias anteriores que envolveram tecidos vizinhos, propôs-se a
A reparação total do lábio superior foi realizada por meio do retalho musculocutâneo, em ilha do depressor do ângulo da boca.

UNITERMOS: Reconstrução de lábio. Músculo depressor do ângulo da boca. Retal hos cirúrgicos.

reparação total do lábio e columela por meio do retalho musculocutâneo do depressor do ângulo da boca (fig. 1).

Anatomia - O estudo anatômico prévio sobre o músculo depressor do ângulo da boca foi realizado $^{1}$, quando se pôde constatar que: a) o músculo depressor do ângulo da boca apresenta forma de trapézio; b) sua irrigação é feita pela artéria labial inferior; c) sua origem é na margem mandibular e sua inserção é ao nível do ângulo da boca; d) o ponto de penetração da artéria labial inferior no músculo dista $22 \mathrm{~mm}$ do ângulo da boca.

Técnica operatória - O planejamento do retaIho é demonstrado nas figs. 1 e 2: a) anestesia local com lidocaína com vasoconstritor; b) incisão na margem superior do retal ho inter essando pele e TCSC; c) dissecção no sentido cranial, com identificação total do músculo (pinçamento reali-

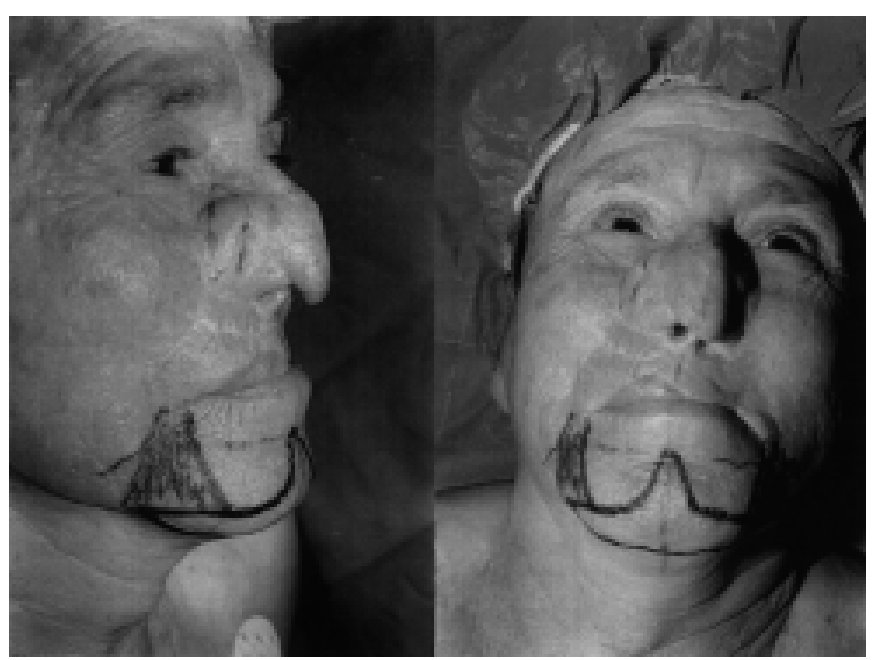

Figs. 1 e 2 - Aspecto pré-operatório. 


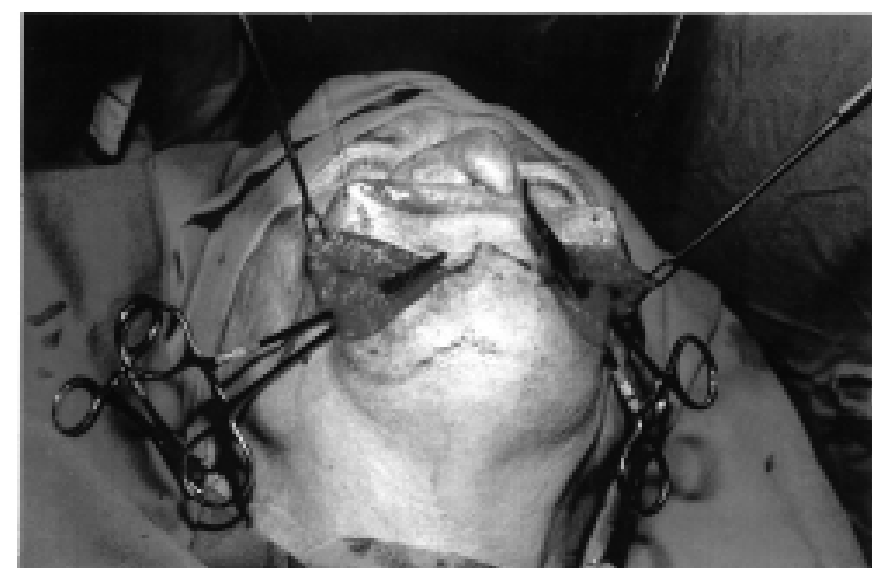

Fig. 3 - Músculo depressor do ângulo da boca dissecado bilateralmente.

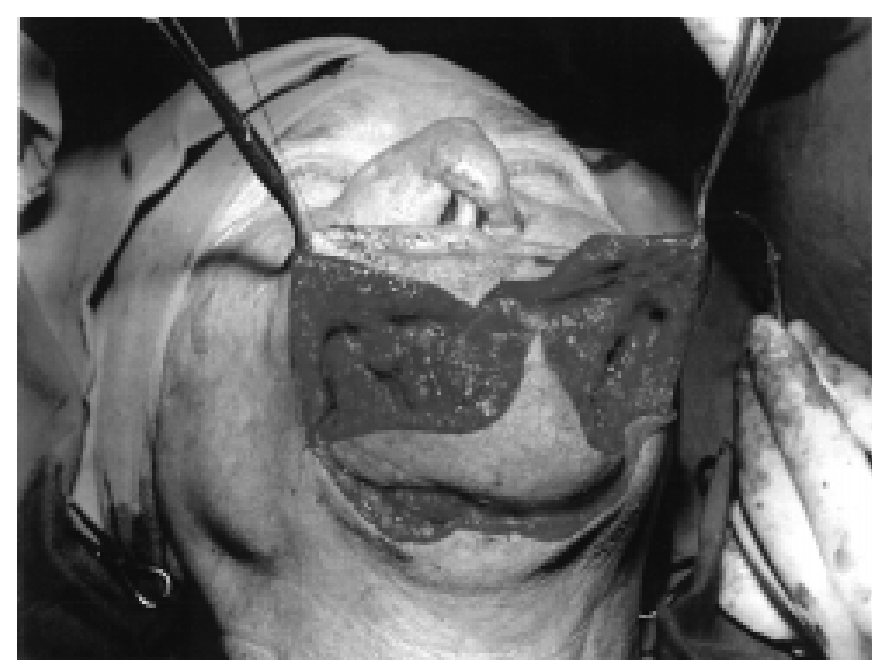

Fig. 4 - Retalho dissecado.

Fig. 5 - Pósoperatório imediato.

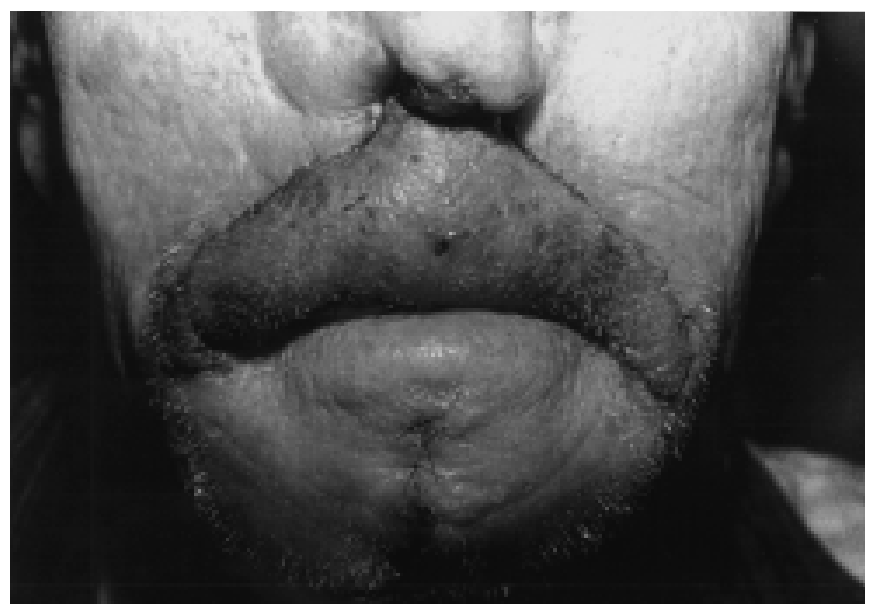

Fig. 6 - Pós-operatório de oito dias.

zado ao nível do ângulo da boca, seguido de tração suave, facilita a identificação) [fig. 3]; d) identificação do pedículo; e) incisão na margem inferior do retalho até o nível de periósteo da mandíbula, sendo o retal ho totalmente liberado (fig. 4); f) abertura de túnel para transferência do retalho; g) acomodação e sutura do retalho em lábio superior e columela (fig. 5).

O paciente teve boa evolução, tendo al ta no quarto dia de pós-operatório.

\section{DISCUSSÃO}

Alguns músculos da mímica facial podem ser incorporados a retalhos locais, conferindo a estes maior segurança e versatilidade.

No caso relatado, utilizamos o músculo depressor do ângulo da boca bilateral, o que proporcionou a transferência de grande quantidade de tecido, suficiente para a reparação total do lábio superior e da columela.

Shaupp ${ }^{2}$ descreve retal ho cutâneo para a reparação do lábio superior com pele das regiões da margem mandibular e mental. Refere a necessidade de se realizar a autonomização do retalho e recomenda tal procedimento para casos de exceção.

O múscul o depressor do ângul o da boca também foi utilizado por Tobin ${ }^{3}$, num retalho musculocutâneo de rotação, para a reparação de perdas parciais do lábio inferior.

O resultado estético da área doadora é de excelente qualidade, sendo realizado por fechamento primário.

O retalho apresentou ótima vitalidade, tendo mostrado apenas pequena área de sofrimento superficial em sua porção central (epidermólise). 


\section{CONCLUSÃO}

O retalho musculocutâneo em ilha do depressor do ângulo da boca é uma nova alternativa para a reparação de perdas complexas do lábio superior, podendo ser utilizado em conjunto para a reparação da columela.

\section{SUMMARY}

Depressor anguli oris myocutaneous island flap for total upper lip and columella reconstruction

Case report of a man that had been previously submitted to many resections of facial skin carcinomas. A serious deformity on the upper lip and col umella remains.
A total upper lip and columella reconstruction through the depressor anguli oris myocutaneous island flap is described. [Rev Ass Med Brasil 1997; 43(2): 151-3]

KEY WORDS: Lip reconstruction. Facial muscles. Flaps.

\section{REFERÊ NCIAS BIBLIOGRÁFICAS}

1. Sabino Neto M. Anatomia do músculo depressor do ângulo da boca. Tese de mestrado. Cirurgia Plástica Reparadora, UNIFESP-EPM, 1995; 71.

2. Schaupp H. Submental hair-bearing skin flap to upper lip. In: Grabb's Encyclopedia of Flaps, $1^{\text {st }}$ ed. Boston, Little, Brown, 1990; 647-8.

3. Tobin GR. Functional lower lip and oral sphincter reconstruction with innervated depresor anguli oris flaps. In: Grabb's Encycl opedia of Flaps, $1^{\text {st }}$ ed. Boston, Little, Brown, 1990; 665-9. 